\title{
The Relationship Between the Foetal Lung and Body at Different Gestational Age of Developing Human Foetuses
}

\author{
Rajeev Mukhia* \\ Department of Anatomy, Manipal College of Medical Sciences, Nepal
}

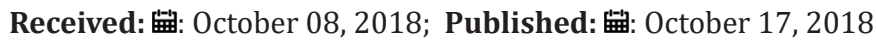

*Corresponding author: Rajeev Mukhia, Department of Anatomy, Manipal College of Medical Sciences, Fulbari, Pokhara, Nepal

\begin{abstract}
Fetal lung is one of the organs of interest for researchers since a long time. Though, detailed morphometric studies about adult lung weight are there in the literature but weight of lungs at different stages in the foetal period is far less available. Hence, the present study attempted to find out the relationship between the foetal lungs in relation with its development in different gestational weeks. The study was carried out on 40 human fetuses of known gestational age in the Department of Anatomy, Manipal College of Medical Sciences, Pokhara, Nepal. Ethical approval was granted by the Institutional Review Committee (IRC), MCOMS, Pokhara. The weight of the fetuses and fetal lung was measured in grams on digital weighing machine. The mean values of all parameters by gestational age was calculated and analyzed. The data was represented graphically by using appropriate statistical analysis. In the present study the body weight of fetuses showed gradual increase from $10^{\text {th }}$ week to $38^{\text {th }}$ weeks of gestation. The weight of right lung was seen more than the weight of left lung throughout the gestational weeks. Evaluating body and organ weights and measurements against known standards is an important part of perinatal pathology and also provides new insights for understanding and developing knowledge in both normal and pathological conditions.
\end{abstract}

Keywords: Human Foetuses; Gestational Age; Foetal Weight; Lung Weight

Abbreviations: IRC: Institutional Review Committee; MCOMS: Manipal College of Medical Sciences; CRL: Crown Rump Length; CHL: Crown Heel Length

\section{Introduction}

The lungs are essential organs of respiration, situated on either side of the heart, and occupy most of the thoracic cavity [1]. The right lung is divided into superior, middle and inferior lobes by its oblique and horizontal fissures. The left lung is divided into superior and inferior lobes by its oblique fissure [2]. The adult right lung usually weighs $625 \mathrm{gm}$, and the left $565 \mathrm{gm}$ [3]. Lung volumes in children vary significantly according to race [4] and lung volume increase linearly with body length [5]. Pulmonary agenesis is a rare congenital abnormality in which lung parenchyma are undeveloped [6]. The development of lung starts as early as fourth weeks of embryonic life from a respiratory bud and continues into postnatal life up to early adulthood $[7,8]$. Fetal lung is one of the organs of interest for researchers since a long time. Since the growth of lung in human fetuses with respect to the gestational weeks in the previous literatures were found to be lacking, hence the present study was done to find out the growth of fetal lung in relation with the gestational week in developing human fetuses.

\section{Materials and Methods}

\section{Study Design}

The present study was carried out on 40 normal human fetuses, aged between $10^{\text {th }}$ to $38^{\text {th }}$ gestational weeks in the Department of Anatomy, Manipal College of Medical Sciences, Pokhara, from March 2017 to August 2018. The normal fetuses were obtained from the Department of Obstetrics and Gynecology, Manipal College of Medical Sciences Teaching Hospital, Fulbari, Pokhara and the fetuses were collected in $10 \%$ formalin for carrying the study.

\section{Ethical Approval}

The study was approved by the Institutional Review Committee (IRC) of Manipal College of Medical Sciences (MCOMS), Pokhara, Nepal.

\section{Inclusion and Exclusion Criteria}

The fetuses included the spontaneous abortion and still born foetuses. Cases with any anomaly or pathology were not included in the study.

\section{Determination of the Age of Foetuses}

The age of foetuses was calculated from the obstetrical history, crown rump length (CRL) and crown heel length (CHL).

\section{Dissection of Foetuses}

The dissection was done according to the Cunningham's manual of practical anatomy $15^{\text {th }}$ Edition and the lungs were removed [9]. 


\section{Weighing of Fetal Body and Lung}

The weight of the foetuses and fetal lungs was measured in grams on digital weighing machine.

\section{Statistical Analysis}

All the data were represented as mean then analyzed with MS Excel 2007 software and represented graphically.

\section{Results}

The present study was carried out in the Department of Anatomy, Manipal College of Medical Sciences, Pokhara. Total 40 human foetuses ranging from $10^{\text {th }}$ to $38^{\text {th }}$ weeks were studied. Measuring weight of human foetuses is shown in Figure 1. Dissection of foetuses and removal of lungs is shown in Figure 2. Measuring weight of right and left fetal lung is shown in Figure 3. The mean values of all parameters by gestational age were calculated. The results of mean body weight, weight of right and left lung and ratio of both lung and fetal weight is shown in Table 1. In the present study the body weight of foetuses showed gradual increase from $10^{\text {th }}$ week to $38^{\text {th }}$ weeks of gestation.

Scatter graph showing weight of foetuses against gestational age is shown in Figure 4. The linear graph showing relationship between foetal lungs and gestational age is shown in Figure 5. The average weight of right lung at $10^{\text {th }}$ week and $38^{\text {th }}$ week was 1.27 and 26.6 gm respectively. The average weight of left lung at $10^{\text {th }}$ week and $38^{\text {th }}$ week was 1.22 and 26.2 gm respectively. The average body weight of foetuses at $10^{\text {th }}$ week and $38^{\text {th }}$ week was 10 and 3101 gm respectively. The relative ratio between lung weight and body weight at $10^{\text {th }}$ week and $38^{\text {th }}$ week are 0.24 and 0.01 respectively.

Table 1: Showing mean body weight, weight of right and left lung and ratio of both lung and fetal weight.

\begin{tabular}{|c|c|c|c|c|c|c|}
\hline $\begin{array}{l}\text { Gestational age } \\
\text { (GA) in weeks }\end{array}$ & $\begin{array}{c}\text { No. of } \\
\text { foetuses }\end{array}$ & $\begin{array}{c}\text { Body weight in } \\
\text { gm }\end{array}$ & $\begin{array}{l}\text { Weight of right } \\
\text { lung in gm }\end{array}$ & $\begin{array}{c}\text { Weight of left lung } \\
\text { in gm }\end{array}$ & $\begin{array}{l}\text { Weight of both lung } \\
\text { in gm }\end{array}$ & $\begin{array}{c}\text { Ratio of both lung } \\
\text { \& body weight }\end{array}$ \\
\hline 10 & 2 & 10.00 & 1.20 & 1.20 & 2.4 & 0.24 \\
\hline 12 & 3 & 12.20 & 1.40 & 1.30 & 2.7 & 0.22 \\
\hline 14 & 2 & 69.25 & 3.40 & 3.10 & 6.5 & 0.09 \\
\hline 16 & 3 & 100.00 & 4.20 & 4.10 & 8.3 & 0.08 \\
\hline 18 & 2 & 197.60 & 5.40 & 5.20 & 10.6 & 0.05 \\
\hline 20 & 3 & 319.25 & 7.60 & 7.20 & 14.8 & 0.04 \\
\hline 22 & 4 & 435.40 & 13.20 & 12.80 & 26 & 0.05 \\
\hline 24 & 3 & 630.00 & 17.40 & 16.60 & 34 & 0.05 \\
\hline 26 & 3 & 766.80 & 18.60 & 17.80 & 36.4 & 0.04 \\
\hline 28 & 2 & 1019.50 & 19.70 & 19.10 & 38.8 & 0.04 \\
\hline 30 & 3 & 1360.00 & 20.20 & 19.80 & 40 & 0.03 \\
\hline 32 & 2 & 1558.00 & 22.40 & 22.10 & 44.5 & 0.03 \\
\hline 34 & 2 & 1925.00 & 23.20 & 22.90 & 46.1 & 0.02 \\
\hline 36 & 3 & 2324.00 & 24.80 & 24.20 & 49 & 0.02 \\
\hline 38 & 3 & 3101.60 & 26.60 & 26.20 & 52.8 & 0.01 \\
\hline
\end{tabular}

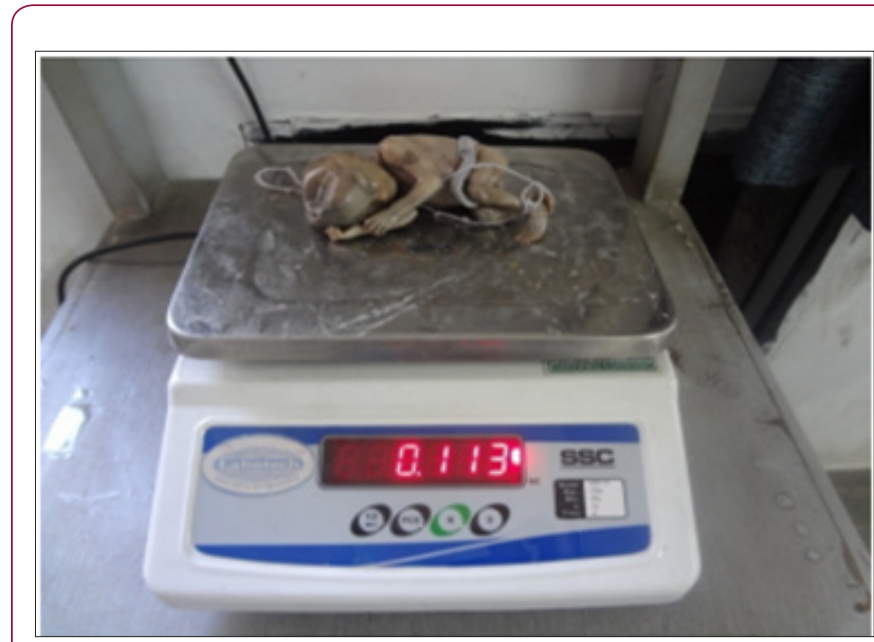

Figure 1: Measuring weight of foetuses at12 gestational age.

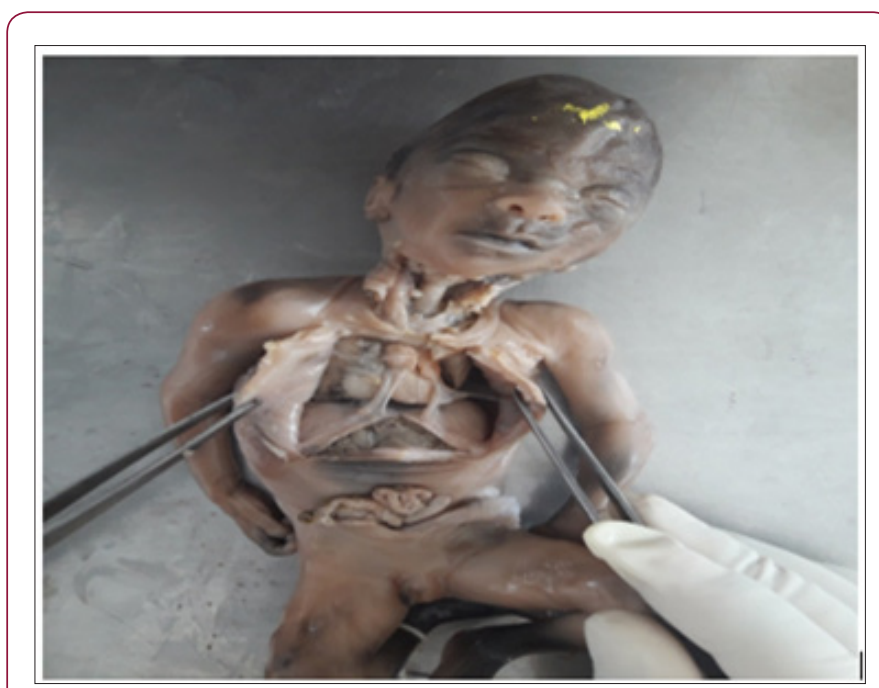

Figure 2: Dissection of foetuses and removal of lungs. 


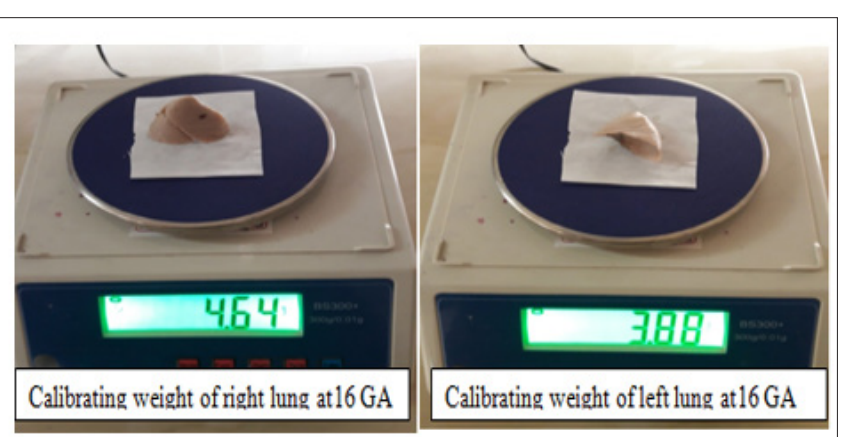

Figure 3: Measuring weight of right and left foetal lung.

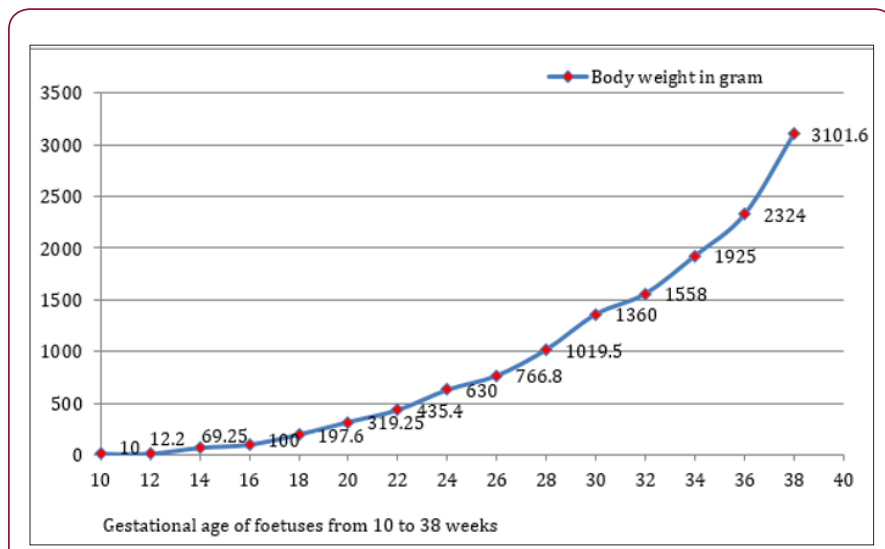

Figure 4: Scatter graph showing weight of foetuses against gestational age.

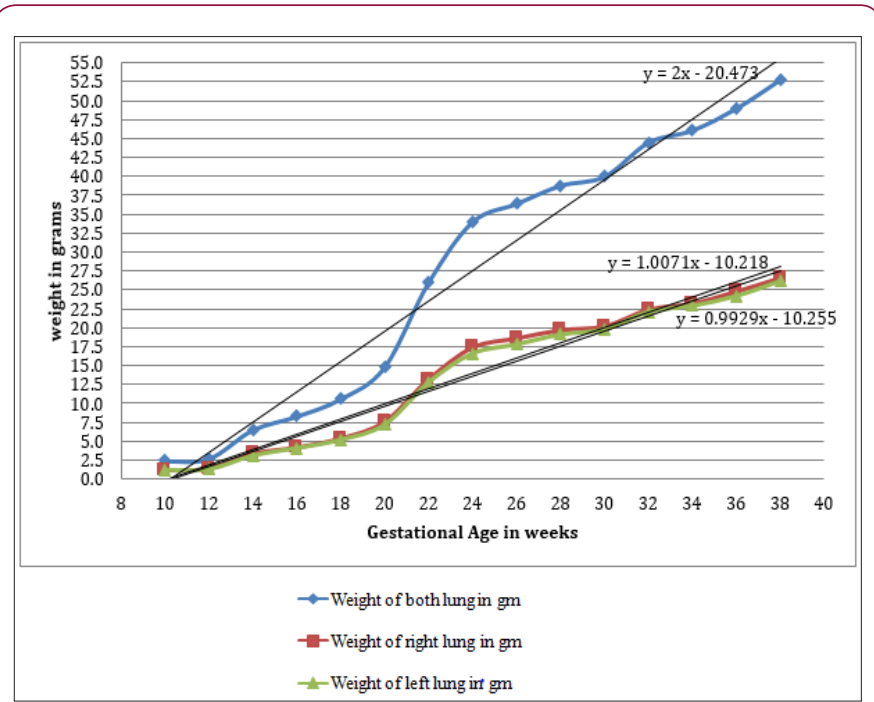

Figure 5: Linear graph showing relationship between foetal lungs and gestational age.

\section{Discussion}

Increase in fetal weight as well as organ weight is a good indicator of fetal growth in general. Rate of weight gain during $1^{\text {st }}$, $2^{\text {nd }}$, and $3^{\text {rd }}$ trimester differs considerably. In the present study the body weight of foetuses showed gradual increase from $10^{\text {th }}$ week to $38^{\text {th }}$ weeks of gestation. The rate of growth of right and left lung showed a minimal value of about $1.80 \mathrm{gm}$ up to $12^{\text {th }} \mathrm{g}$. W. and thereafter showed a gradual increase from $14^{\text {th }}$ to $20^{\text {th }} \mathrm{g}$. $\mathrm{w}$. and then showed a moderately rise and was found to be almost similar up to $24^{\text {th }} \mathrm{g}$. W. recording an average weight of $18 \mathrm{gm}$. Throughout the gestational period, the growth rate of right lung was found little faster than that of left lung. At $38^{\text {th }}$ g.w., the right lung recorded $26.6 \mathrm{gm}$ whereas the left lung recorded $26.2 \mathrm{gm}$. The linear graph in Figure 4, shows the comparison of growth rate of left and right lungs with increase in gestational weeks in human foetuses.

In the present study, the differential growth rate of the lung weight/body weight ratios with increase in gestational weeks was observed as follows: a mild fall was there from $10^{\text {th }}$ to $14^{\text {th }}$ g.w., then a gradual decrease from $14^{\text {th }}$ to $18^{\text {th }}$ g.w. Thereafter, a moderately increase was seen from $22^{\text {nd }}$ to $24^{\text {th }} \mathrm{g}$. w. and then a gradual fall up to $28^{\text {th }}$ g.w. Then, there is a gradual decrease from $28^{\text {th }}$ g.w. to 30 th g.w. and finally remained almost constant up to $36^{\text {th }}$ g.w. The ratio becomes 0.01 at the end of $38^{\text {th }}$ g.w. Tanimura et al. [10] reported that the lung weight to body weight ratio was found to be increasing and then decreasing and the ratio reached the maximum at $12-14^{\text {th }}$ weeks of gestation [10], which is almost similar found in conformity with the finding of the present study except for some findings in some weeks of gestation which may be deviated due to difference in sample size of study, genetic and environmental factors which may affects the fetal and lung development.

The results of the present study compare closely with smaller studies which was done by Shepard TH et al. [11] Another study which was done by G. Mitropoulos et al. [12] was that all organ weights/body weights were found almost constant after $30^{\text {th }}$ weeks gestation, which is found to be in conformity with the finding of the present study. In conclusion, we confirm that in the normally developing foetuses the body and lung weight increases with advancing gestational age, but the weight of right lung was seen more than the weight of left lung throughout the gestational age. Evaluating body and lung weights and measurements against known standards is an important part of perinatal pathology. It also provides new insights to the anatomist and clinician for understanding and developing knowledge in both normal and pathological conditions of pulmonary tissue.

\section{Acknowledgement}

The author expresses special thanks to all the faculties and nonteaching staff members of Anatomy Department, MCOMS, Pokhara for their guide and support.

\section{References}

1. Standring S (2008) Gray's Anatomy; the anatomical basis of clinical practice, in ( $40^{\text {th }}$ edn.) Elsevier, 1428-1430 Edinburgh, Churchill Livingstone.

2. Risse C, Gaddum and Rosse P (1997) Hollinshed's Text book of Anatomy. Philadelphia, In: Lipincot-Raven (Eds.). pp. 441-461.

3. Thurlbeck WM (1982) Postnatal human lung growth, Thorax 37: 564571.

4. Sylvester KP, Milligan P, Patey RA, Rafferty GF, Greenough A (2005) Lung volumes in healthy Afro- Caribbean children aged 4-17 years. Pediatr Pulmono 40: 109-112.

5. Rao L, Tiller C, Coates C, Kimmel R, Applegate KE, et al. (2010) Lung growth in infants and toddlers assessed by multi-slice computed tomography. Acad Radiol 17: 1128-1135. 
6. Nabati M, Bagheri B and Habibi V (2013) Coincidence of congenital agenesis of left lung and common atrium: a very rare case. Echocardiography 30: 132-135.

7. Keith L Moore (2016) The Developing Human Clinically Oriented Embryology in: (10th Edn.). Philadelphia / Elsevier pp. 196-207.

8. Krishna Garg (2012) BD Chaurasia Human Embryology. In: (2nd eds.) CBS Publishers \& Distributors pp. 201-207.

9. GJ Romanes (1986) Cunningham's manual of practical anatomy in: (15th edn.). Oxford medica publication, Vol 2 Thorax and Abdomen p. 34-42.

ISSN: 2574-1241

DOI: 10.26717/BJSTR.2018.10.001908

Rajeev Mukhia. Biomed J Sci \& Tech Res

(C) (P) This work is licensed under Creative

Submission Link: https://biomedres.us/submit-manuscript.php
10. Tanimura T, Nelson T, Hollingsworth RR and Shepard TH (1971) Weight standards for organs from early human fetuses. Anat Res 171: 227-236.

11. Shepard TH, Shi M, Fellingham GW, Fujinaga M, Fitz Simmons JM, (1988) Organ weight standards for human fetuses. Pediatr Pathol 8(5): 513524 .

12. Mitropoulos G, Scurry J, Cussen L (1992) Organ weight/body weight ratios: growth rates of fetal organs in the latter half of pregnancy with a simple method for calculating mean organ weights. J Paediatr Child Health: 28(3): 236-239.

$\begin{array}{ll}\text { BIOMEDICAL } & \text { Assets of Publishing with us } \\ \text { RESEARCHES } & \text { - Global archiving of articles } \\ \text { - Immediate, unrestricted online access } \\ \text { - Rigorous Peer Review Process }\end{array}$

